OLVEIRA, Luciana Rodrigues; MAGALHÃES, Joanalira Corpes. Esse é o Show da Luna: investigando gênero, ensino de ciências e pedagogias culturais. Domínios da imagem, v. 11, n. 20, p. 95-118, jan./jun. 2017.

ISSN 2237-9126

Recebido em 28/04/2017 e aprovado em 07/08/2017

\title{
ESSE É O SHOW DA LUNA: INVESTIGANDO GÊNERO, ENSINO DE CIÊNCIAS E PEDAGOGIAS CULTURAIS
}

\section{THIS IS LUNA'S SHOW: INVESTINTIGATING GENDER, TEACHING SCIENCES AND CULTURAL PEDAGOGIES}

Luciana Rodrigues de Oliveira

Resumo: Este artigo, tem como objetivo discutir as questões de gênero, ensino de ciências e pedagogias cultura is a partir do desenho animado 0 Show da Luna, bem como analisar as percepções de algumas crianças, de uma escola do município do Rio Grande/RS, acerca desse artefa to cultural1. O trabalho se fundamenta a partir dos Estudos Cultura is e de Gênero, nas vertentes pós-estruturalistas. Enquanto metodologia de análise dos dados utilizamos a Análise Cultural. Nas a nálises realizamos dois movimentos: no primeiro disc utimos as potencia lidades pedagógicas do desenho a nalisado; no segundo movimento investigamosa fala das crianças participantes.

Palavras chave: Artefa tos cultura is. Ciências. Gêneros. Peda gogias cultura is.

Abstract This article, aims to disc uss issues of gender, science teaching and cultural pedagogies from the cartoon Earth to Luna and analyze the perception of some children in a school in the municipa lity of Rio Grande / RS, this cultural artifact. The work is based on the Cultural and Gender Studies, in the poststructuralist aspects. As a methodology of data analysis we used the Cultural Analysis. In the analysis we made two movements: in the first, we discussed the pedagogical potential of the analyzed design. In the second movement, we investigated the speech of the participating children.

Keywords: Cultural artifacts. Science. Genders. Cultural pedagogies.

\section{Introdução}

Os Artefatos Cultura is são vá rias produções resultantes de processos de construção social e cultural. Neste trabalho estamos considerando o desenho O Show da Luna enquanto um artefato cultural, o qual é direcionado àscriançase trata de temáticas relacionadas à ciência.

\footnotetext{
- Universidade Federal do Rio Grande - FURG, Graduada em Pedagogia Licencia tura.

- Universidade Federal do Rio Grande - FURG, Professora Adjunta do Instituto de Educação, Doutora em Educação em Ciências.

${ }^{1} \mathrm{O}$ estudo foi construído como trabalho de conclusão do curso de Pedagogia Licenciatura da Universida de Federal do Rio Grande - FURG .
} 
OLVEIRA, Luciana Rodrigues; MAGALHÃES, Joanalira Corpes. Esse é o Show da Luna: investigando gênero, ensino de ciências e pedagogias culturais. Domínios da imagem, v. 11, n. 20, p. 95-118, jan./jun. 2017.

ISSN 2237-9126

O desenho apresenta a Ciência de forma lúdica, desconstruindo e (re) construindo o modo de se 'fazer' ciência, bem como evidencia a presença de meninas nessa prática. Ao analisar outros desenhos que trazem personagens cientistas nos canais fechados de televisão, observamos personagens como o Dexter (O Laboratório de Dexter), o Heinz Doofenshimirtz (Phineas e Ferb), o Professor (As meninas superpoderosas), as garotas Susan e Mary (J ohnny Test) e o J immy Neutron (J immy Neutron).

Esses desenhos citados apresentam uma imagem tradicional sobre Ciência, percebida quando analisamos as caractenísticas e cenário desses artefatos. Todos os personagens, com exceção do J immy Neutron que utiliza somente seu jaleco quando entra em seu laboratório, estão sempre vestidos com seus jalecos brancos; Dexter e as imãs gêmeas Susan e Mary usam óculos; Dexter às vezes usa sua immã Didi como cobaia, já as imãs Susan e Mary usam seu imão J ohnny; além disso as immãs usam a ciência para criar produtos com o propósito de conquistar seu vizinho, pelo qual são apaixonadas. Todos esses personagens se dedicam diariamente à ciência, geralmente trabalham sozinhos em suas experiências científicas, às vezes mencionando grandes cientistas da sociedade, tais como Albert Einstein ${ }^{2} \mathrm{e}$ Charles Darwin 3 .

O desenho animado $O$ Show da Luna nos apresenta uma outra possibilidade de pensar a ciência, os elementos que envolvem a atividade científica e os/as cientistas. Com isso é possível problematizar como essa personagem e esse desenho podem vir a criar outros significados sobre gênero e sobre ciência, bem como esse artefato se apresenta enquanto uma potente ferramenta pedagógica para discussão desses temas no espaço da escola.

Neste sentido, temos como objetivo neste trabalho discutir as questões de gênero, ensino de ciências e pedagogias cultura is a partir do desenho

\footnotetext{
2 Físic o teórico alemão, responsável pelo desenvolvimento da Teoria da relativida de geral.

3 Naturalista britânic o reconhecido pela Teoria da Evolução.
} 
OLVEIRA, Luciana Rodrigues; MAGALHÃES, Joanalira Corpes. Esse é o Show da Luna: investigando gênero, ensino de ciências e pedagogias culturais. Domínios da imagem, v. 11, n. 20, p. 95-118, jan./jun. 2017.

ISSN 2237-9126

animado O Show da Luna, bem como analisar as percepções de algumas crianças, de uma escola do município do Rio Grande/RS, acerca desse artefa to cultural.

\section{Tecendo alguns conceitos teóric os}

Alguns sujeitos percebem que a Ciência tem como propósito explicar de modo racional fenômenos, teorias, acontecimentos, entre outras questões. Segundo Silva (1998, p.13) a “Ciência se refere a descobrir e explicar. É baseada em observação, razão, em experimentação estruturada, e na revisão de resultados". Em nossa sociedade e no campo educacional a ciência, na maioria das vezesé entendida enquanto uma área produtora de saberes e verdades absolutas e inquestionáveis. Conforme Schwantes, (2014, p. 45)

quem faz Ciência e quem usa as metodologias da Ciência são os cientistas em seus laboratórios. Eles são vistos, pela maioria das pessoas e também pela mídia, como pessoas neutras, que, quando entram em seus laboratórios, deixam todos seus "problemas" e visões de mundo fora deste.

Assim, através do método científico o conhecimento é produzido e considerado como válido, inquestionável e seguro. O filósofo austríaco Feyerand, conforme destaca Schwantes, (2014, p. 45),

[...] por meio de suas pesquisas e seus livros, tem questionado muito a questão do método único utiliza do pela Ciência. Ele sustenta que não há como, dada à diversidade de pesquisas, de perguntas e de fenômenos que podemos descobrir, existir um único método para todas as descobertas.

Entendemos que a ciência está em constante tranformação e não é incontestável. Sua produção é humana e contingente, visto que os/as cientistas possuem seus valores, crenças e visões de mundo particulares. 
OLVEIRA, Luciana Rodrigues; MAGALHÃES, Joanalira Corpes. Esse é o Show da Luna: investigando gênero, ensino de ciências e pedagogias culturais. Domínios da imagem, v. 11, n. 20, p. 95-118, jan./jun. 2017.

ISSN 2237-9126

Contudo, não estamos desconsiderando a ciência enqua nto um campo de produção de saberes, mas sim procuramos tomá-la como um campo em constante produção. A ciência é uma construção humana, isto é, uma construção social permeada por questões socioculturais, políticas e econômic as. Conforme Maga lhães (2012, p. 24), “os conhec imentos não são descobertos em um determinado momento, devido a determinadas circunstância, mas, sim, são produzidos, inventados e essa produção encontra-se engendrada a relações de poder-saber".

Essas relações de poder-saber são percebidas quando a nalisamos as contribuições de Agostino Bassi4 para a Teoria Modema Microbiana, pois o fato de Bassi ser um administra dor de propriedades rura is, seu experimento foi questionado e experimentado através de outro método por membros de uma comissão de uma universidade italiana. Esse exemplo mostra o quão forte as relações de poder estão implicadas nos processos de "produção, validação e divulgação de conhec imentos científic os" (ROSA, 1997, p. 53).

Podemos pensar ta mbém o quanto, na história da ciência, as mulheres aparecem a margem da sociedade e dessa história. Rosa (1997, p. 54), cita Donna Haraway ao discutir que nos estudos científicos de uma forma ou de outra o feminino aparece como sendo inferior ao masculino. Nos livros didáticos, por exemplo, na maioria das vezes são cientistas homens que são ilustrados, como se não houvessem cientistas mulheres na história da ciência . Assim, a Teoria da Evolução, nega a participação das mulheres nesse período.

Todas as desc rições referem-se exc lusivamente ao homem préhistórico, todas as ações e todos os adjetivos são masculinos: “homem pré-histórico, homem-a rtesão, caçadores-coletores, criador de artefatos e manipulador de materiais". (ROSA, 1997, p. 56)

\footnotetext{
4 Para saber ma is leia o texto "Repensando o ensino de Ciências a partir de novas histórias da ciência" da autora Russel Teresinha Dutra da Rosa.
} 
OLVEIRA, Luciana Rodrigues; MAGALHÃES, Joanalira Corpes. Esse é o Show da Luna: investigando gênero, ensino de ciências e pedagogias culturais. Domínios da imagem, v. 11, n. 20, p. 95-118, jan./jun. 2017.

ISSN 2237-9126

Para visibilizar a histónia e participação das mulheres em nossa sociedade emergem os Estudos de Gênero. Numa perspectiva pósestrutura lista, iremos dissertar sobre a construção e significação da palavra gênero nesses estudos.

No século XIX, no Ocidente, segundo Louro (2013) inicia-se um movimento feminista organizado, são manifestações contra a opressão das mulheres. Essas manifestações tiveram maior visibilidade e expressão no chamado "sufragismo", ou seja, um movimento voltado para que a mulher tivesse direito ao voto, pois a té então somente os homens tinham esse direito assegurado. Após alastrar-se por vários países do Ocidente, esse movimento fic ou conhecido como sendo a "primeira onda" do feminismo.

Ao final da década de 1960 inicia-se o desdobramento da "segunda onda", a qual a preocupação do feminismo vai além das questões socia is e políticas. Volta-se para as construções teóricas e problematizam a questão de gênero. Louro (2013), nos mostra que estudiosas feministas diferenciaram os temos Gênero e Sexo, com o objetivo de romper com a concepção de que ambos estão ligados. Mas isso não significa que tais estudiosas negassem a biologia, mas sim buscavam considerar a construção histórica e social produzidas pelas caracteństic as biológicas, como são compreendidas e representadas.

Historicamente, observamos a construção de argumentos que justificavam as desigualdades socialmente construída entre homens e mulheres. Isso ocomia pelo fa to de que o homem era visto como patriarca da família, como o centro das relações em todos os âmbitos. O homem trabalhava enquanto que a mulher fic ava em casa cuidando dos afazeres domésticose dos/as filhos/as (se houvessem). De acordo com Louro (2013, p. 24-25) existem pessoas 
OLVEIRA, Luciana Rodrigues; MAGALHÃES, Joanalira Corpes. Esse é o Show da Luna: investigando gênero, ensino de ciências e pedagogias culturais. Domínios da imagem, v. 11, n. 20, p. 95-118, jan./jun. 2017.

ISSN 2237-9126

[...] que justificam a desigualdade social entre homens e mulheres, remetendo-as, geralmente, às características biológicas. O argumento de que homens e mulheres são biologicamente distintos e que a relação decorre dessa distinção, que é complementar e na qual cada um deve desempenhar um papel deteminado seculamente, acaba por ter o caráter de argumento final, irrecomível. Seja no âmbito do senso comum, seja revestido por uma linguagem "científica", a distinção biológica, ou melhor, a distinção sexual, serve para compreender - e justific ar - a desigualdade social. (grifos da autora)

Essa desigualdade era tanto na esfera pública quanto na privada. A primeira, é percebida pela pouca participação das mulheres na ciência, na política e nos espaços públicos. A segunda, é fortemente vinculada com a função do papel doméstico.

Para Louro,

[...] É necessário demonstrar que não são propriamente as caracteństicas sexuais, mas é a forma como essas carac terístic as são representadas ou va lorizadas, a quilo que se diz ou pensa sobre elas que vai construir, efetivamente, o que é feminino ou masculino em uma dada sociedade e em um dado momento histórico. Para que se compreenda o lugar e as relações de homens e mulheres numa sociedade importa observar não exatamente seus sexos. O debate vai se constituir, então, por meio de uma nova linguagem, na qual gênero será um conceito fundamental. (2013, p. 25) (grifos da autora)

Para entendemos o que é gênero, temos que ir além da relação homem/mulher, masculino/feminino e buscar compreender as relações sociais e históricas envolvidas nesse processo de construção. A produção da identidade de um sujeito é um processo constante já que o mesmo tende a questiona r-se enqua nto um ser so cial, com cara c teństicas próprias.

[...] Numa aproximação às formulações mais críticas dos Estud os Feministas e dos Estudos Cultura is, compreendemos os sujeitos como tendo identidades plurais, múltiplas; identidades que se transformam, que não são fixas ou permanentes, que 
OLVEIRA, Luciana Rodrigues; MAGALHÃES, Joanalira Corpes. Esse é o Show da Luna: investigando gênero, ensino de ciências e pedagogias culturais. Domínios da imagem, v. 11, n. 20, p. 95-118, jan./jun. 2017.

ISSN 2237-9126

podem, até mesmo, ser contraditórias. Assim, o sentido de pertencimento a diferentes grupos - étnicos, sexuais, de classes, de gênero, etc. - constitui o sujeito e pode levá-lo a se perceber como se fosse "empurado em diferentes direções", como diz Stuart Hall(1992, p. 4) ao afimar que o gênero institui a identidade do sujeito(assim como a etnia, a classe, ou a nacionalidade, por exemplo) pretende-se referir, portanto, a algo que transcende o mero desempenho de papéis, a ideia é perceber o gênero fazendo parte do sujeito, constituindo-o [...](LOURO, 2013, p. 28-29). (grifos da autora)

Com isso, destacamos a importância dos Estudos Feministas e dos Estudos Culturais para o entendimento da construção das identidades do sujeito e dosgêneros como parte dessas.

Pensar os gêneros enquanto construções é pensar que somos educados/as para além do espaço da escola. Nesse sentido, construímos nossos entendimentos sobre o que é ser homem e ser mulher em diversos espaços os quais frequentamos. Para tanto, estamos trabalhando com o entendimento de artefatos culturais, enquanto produtores de conhecimentos, modos de sere estar no mundo.

Os a rtefatos cultura is tais como: televisão, revistas, museus, dentre outros espaços, produzem conhecimentos e significados, nos quais transmitem ideias e conhecimentos e assim podemos dizer que produzem uma pedagogia cultural. De acordo com Magalhães (2012, p. 38), “[...] Essas pedagogias cultura is não podem ser tomadas como neutras, pois produzem e ensinam saberes, condutas e identidades".

As pesquisas no campo da cultura e da pedagogia contribuíram e contribuem para que possamos entender melhor esses espaços que ta mbém geram conhecimento. Para Andrade (2015) o conceito de pedagogias cultura is é uma a mpliação da ideia dos espaços de aprendizagem. A autora destaca a ideia de que ensino e aprendizagem não se restringem as salas de aula e é permeado pelas relações de poder.

Ao investigar o desenho $\mathrm{O}$ Show da Luna, temos uma menina cientista e que faz suas pesquisas em casa, na rua, a partir de questionamentos que 
OLVEIRA, Luciana Rodrigues; MAGALHÃES, Joanalira Corpes. Esse é o Show da Luna: investigando gênero, ensino de ciências e pedagogias culturais. Domínios da imagem, v. 11, n. 20, p. 95-118, jan./jun. 2017.

ISSN 2237-9126

surgem no seu dia a dia. Quando comparamos esse desenho a os outros citados anteriomente, percebemos que os mesmos a presentam como deve ser um cientista; com isso esses artefatos acabam por ensinar que só pode ser cientista quem é homem, vestindo jaleco e em um laboratório. Isso nos mostra que "essas pedagogias produzem significados, representações e saberes que acabam por educar os sujeitos, ensinando modos de ser, estare perceber o mundo, a si e aosoutros" (MAGALHÃES, 2012, p. 38).

Assim, busc a mos a mpliar nossos olhares para estes artefa tos cultura is, buscando as suas potencialidades, com o objetivo de investigar e discutir as questões de gênero e ciência a partir deste artefa to cultural - o desenho $O$ Show da Luna - bem como analisar as percepções de algumas crianças com idades entre 7 e 8 anos, do segundo ano do ensino fundamental de uma escola do município do Rio Grande/RS, acerca deste desenho.

\section{Sobre a fonte e a metodologia}

O desenho O Show da Luna foi criado por Célia Catunda e Kiko Mistrorigo. Em 2006 a ideia da personagem Luna começou a ser pensada, mas somente em 2010 que o projeto de animação começou. A série tem como público alvo crianças de 3 a 5 anos 5 .

Luna é uma menina de 6 anos muito curiosa que adora fazer perguntas do cotidiano e que ama ciências. Luna sempre está com um bloco de notas, câmera, lente de aumento e caixa de som. Júpiter seu imão e tem 4 anos. Ele sempre tem alguma explicação mágica para os fenômenos, e está sempre preparado em ajudar sua imã em suas novas descobertas. Cláudio é um furão de estimação da Luna, que sempre a acompanha em suas investigações. Cláudio no faz de conta fala e expressa

\footnotetext{
${ }^{5}$ Fonte https://pt.wikipedia.org/wiki/O_Show_da_Luna.
} 
OLVEIRA, Luciana Rodrigues; MAGALHÃES, Joanalira Corpes. Esse é o Show da Luna: investigando gênero, ensino de ciências e pedagogias culturais. Domínios da imagem, v. 11, n. 20, p. 95-118, jan./jun. 2017.

ISSN 2237-9126

todas suas ideias e sentimentos, já no mundo real ele apenas faz gestos, expressões, grunhidos e barulhos.

Conforme entrevista concedida ao site G1, Célia Catunda, uma das criadoras do desenho, afima que "a personagem surge do traço em primeiro lugar. Certa vez eu desenhei um esboço sem muito compromisso e, a partir daí, comecei a pensar numa protagonista feminina, forte, e me ocorreu falar em ciência, do ponto de vista da curiosidade" (ALVARENGA, 2016).

Na mesma entrevista o também criador do desenho, Mistronigo, argumenta que "a Luna traz uma protagonista feminina, o que já não é muito comum. E é uma menina sem frufru. Além disso, a série não tem nenhum adulto, máquina ou Google que tira as dúvidas. É ela que vai atrás e, pela imaginação, consegue formular as próprias hipóteses e tirar as conclusões" (ALVARENGA, 2016).

A produção do desenho conta com o apoio do BNDES (Banco Nacional do Desenvolvimento), FINEP (inovação e pesquisa), Secretaria do Audiovisual, Ministério da Cultura, Ministério da Ciência, Tecnologia e Inovação do Govemo Federal. Sua estreia no Brasil foi no dia 13 de outubro de 2014, pelo canal Discovery Kids, coprodutor da série. A primeira exibição pelo canal aberto ocorreu em 10 de agosto de 2015, pela TV Brasil, no programa "Hora da criança".

O seriado tem três temporadas. Nas duas primeiras temporadas a duração média de cada episódio é de 12 minutos e na terceira são 15 minutos. A cada episódio uma temática é abordada, como por exemplo: as cores, a vida dos animais, alimentos, questões sobre a água, universo, etc. Luna utiliza sua imaginação para responder a suas dúvidas, essas questões surgem em qualquer lugar onde ela estiver, seja no quintal de sua casa ou na praia. Com a ajuda do seu imão e o furão de estimação, formulam hipóteses e fazem experimentos para solucionar suas problemáticas. 
OLVEIRA, Luciana Rodrigues; MAGALHÃES, Joanalira Corpes. Esse é o Show da Luna: investigando gênero, ensino de ciências e pedagogias culturais. Domínios da imagem, v. 11, n. 20, p. 95-118, jan./jun. 2017.

ISSN 2237-9126

Os episódios do desenho O Show da Luna analisados neste trabalho estão disponíveis no YouTube (https://www.youtube.com.). ${ }^{6}$ Os episódios assistidos foram: "Borboleta Luna", "Asas para voar" e "Como a água vira chuva?". Durante as atividades desenvolvidas realizava algumas intervenções com as crianças e, assim, perguntava a elas: "O que é Ciência?", com o objetivo de conhecer aspercepções e visões que elas têm sobre esse assunto. Após mostrar os vídeos selecionados, fazia alguns questiona mentos a cerca do entend imento dessas crianças, como: "Em qual momento do vídeo vocês perceberam ou não que havia Ciência sendo feita?"; "Vocês já assistiram outros desenhos relacionados à Ciência?". Se não fossem feitos comentários sobre a Luna ser uma cientista, perguntava sobre o que achavam de uma menina ser a cientista.

O primeiro episódio assistido foi a "Borboleta Luna". Nesse episódio Luna, Júpiter e Cláudio estavam dentro de casa quando Luna observou uma borboleta pousando em frutas, flores dentre outros objetos que estavam no local. Ao pousara borboleta esfregava suas patinhas. Então Luna perguntou: Por que as borboletas fazem isso? O que está acontecendo aqui? Tentando responder seus questionamentos, Luna colocou em uma mesa algumas frutas, suco e uma borracha em forma de bolinho para ver o que a borboleta ina fazer. Então a borboleta apareceu, pousou nas frutas, menos na borracha. Para descobrir porque isso ocorreu Luna e seus ajudantes, usando a imaginação, transformaram-se em borboletas e descobriram que elas usam as patinhas para sentirem os sabores dos alimentos e distinguir objetos. Também descobriram que as borboletas pisam nas flores e espalham seu pólen.

No episódio "Asas para voar" Luna, Júpiter e Cláudio estavam brincam de fazer dobraduras no quintal, e o avião de papel que o Júpiter fez caiu em um ninho de passaninhos. Quando foram buscar o avião, Luna observou o

${ }^{6}$ Os episódios foram seleciona dos tendo como critério as a tividades e disc ussões previstas em proposta de está gio realiza do no curso de Pedagogia. 
OLVEIRA, Luciana Rodrigues; MAGALHÃES, Joanalira Corpes. Esse é o Show da Luna: investigando gênero, ensino de ciências e pedagogias culturais. Domínios da imagem, v. 11, n. 20, p. 95-118, jan./jun. 2017.

ISSN 2237-9126

primeiro vôo de um filhote de passarinho. Então se perguntou: Como aquele filhote aprendeu a voar? Quem ensinou? Como os pássaros voam? Ao tentar responder a essas perguntas Luna pediu para que seu imão Júpiter e seu a nimal de estimação, Cláudio, fizessem dois aviões de papel. No avião de seu imão havia um boneco e no outro nenhum objeto foi colocado. Ao jogarem os aviões perceberam que o avião do Cláudio, que estava sem o boneco, voou mais longe porque era mais leve. Então surgiu outro questionamento: Será que os pássaros voam por que são leves? Para responder seus questionamentos, os personagens transformaram-se em pássaros, e através dessa forma lúdica descobriram que os pássaros conseguem voar devido aos seus ossos porosos e que por causa dessa estrutura eles são levese isso ajuda no vôo.

No último vídeo sobre "como a água vira chuva", Luna e seu imão estão tomando água quando sua mãe diz algo que atiça a curiosidade de Luna. Eis que surge uma pergunta: Como que aquela água toda que estão bebendo pode virar chuva? Para responder a ma is esse questionamento, os três (Luna, Júpiter e Cláudio) fazem um experimento, porém o mesmo não foi suficiente para responder as suas dúvidas. Então usando a imaginação todos se transfomaram em uma nuvem e descobriram que a água quando evapora forma nuvens e quando as nuvens "batem" uma na outra chove.

Após assistir os episódios, fizemos as perguntas separadamente, para que não houvesse interferência na resposta de cada um/a dos/as estudantes, já que observei que as crianças que entrevistei baseavam-se nas respostas dos/as outros/as. Utilizei uma câmera para poder gravar suas falas. Para registrar suas falas, utilizei como recursos: a notações e gravações, estes dois recursos possibilitam analisar de forma mais segura e aproximada as falas das crianças. ${ }^{7}$

\footnotetext{
7 Das vinte e uma crianças somente quinze quiseram responder as perguntas, porém não obtive pemissão dos/as responsáveis por duas crianças para poder analisar suas falas. Assim, compuseram a análise dos dados treze respostas.
} 
OLVEIRA, Luciana Rodrigues; MAGALHÃES, Joanalira Corpes. Esse é o Show da Luna: investigando gênero, ensino de ciências e pedagogias culturais. Domínios da imagem, v. 11, n. 20, p. 95-118, jan./jun. 2017.

ISSN 2237-9126

Enquanto metodologia de análise dos dados, utilizamos a Análise Cultural, ancoradas a partir dos Estudos Culturais, em suas vertentes pósestrutura listas. $\mathrm{Na}$ a ná lise cultural, exa minamos os artefa tos cultura is visa ndo problematizar as representações sociais (re)produzidas, as origens dessas invençõese os processos pelos qua is se to maram "na tura liza das", bem como qua is signific a dos e entendimentos são construídos pelos sujeitos a partir dos artefatos culturais, no caso a fala das crianças sobre o desenho a nimado $O$ Show da Luna.

Nas a ná lises va mos rea lizar do is movimentos: no primeiro va mos disc utir as potencialidades pedagógic as do desenho analisado neste trabalho e, no segundo, vamosinvestigara fala das crianças participantes.

\section{Primeiro movimento}

O desenho animado O Show da Luna traz questionamentos sobre os fenômenos que estão presentes em nosso cotidiano. Através de elementos como a imaginação, em que através dela as/os personagens fazem descobertas resultantes das interações deles/as com o objeto de investigação. As questões que aparecem nesse desenho são do cotidiano dos sujeitos e as argumentações presentes no mesmo, mostra o potencial para ser trabalhado com as crianças. Incentivando a construírem novas perguntas, buscarem respostas, fazerem novas descobertas e explorar o potenciale imaginação de cada criança.

Luna sempre faz questionamentos sobre os acontecimentos de seu cotidiano. Com as crianças e também com os adultos, acontece o mesmo. Quando não conhecêssemos algo queremos saber sobre, então para tentar responder nossas perguntas nos fazemos questionamentos que talvez consigamos ou não obter respostas. Nesse processo estamos fazendo Ciência, já que 
OLVEIRA, Luciana Rodrigues; MAGALHÃES, Joanalira Corpes. Esse é o Show da Luna: investigando gênero, ensino de ciências e pedagogias culturais. Domínios da imagem, v. 11, n. 20, p. 95-118, jan./jun. 2017.

ISSN 2237-9126

[...] a ciência procura explicartudo que ocorre ao nosso redor, partindo de problemas, curiosidades, dúvidas e questionamentos que fazemos por meio do olhar que damos às coisas do mundo. Assim, a Ciência pode ser entendida como algo que está relacionado à cultura, às relações sociais e também ao conhecimento científico que vem sendo produzido ao longo dos anos e que se constitui como um importante campo do saber. (ÁVILA, QUADRADO, BARROS, 2014, p. 34)

Este artefato cultural abre um leque de possibilidades de o/a educador/a trabalhar em sala de aula questões que envolvam múltiplos conhecimentos. Principalmente sobre a natureza. Por exemplo, nos episódios que apresentei e trabalhei com as crianças pude explorar os estados físicos da água (sólido, líquido e gasoso), no episódio da borboleta discutimos como as borboletas sentem os gostos e também o fenômeno da metamorfose. No outro episódio trabalhamos a temática das aves e porque elas conseguem voar. Assim como esses, os outros episódios do desenho 0 Show da Luna, nos faz pensar em trabalhar com as cores, arco-íris, os planetas, os dinossauros, as frutas, dentre outras temáticas relacionadas à Ciência. As diversas temáticas que o desenho traz propiciam discutir a ciência de forma lúdica e com uma linguagem adequada para ascrianças.

Também nos possibilita discutir sobre a história das mulheres na Ciência, já que a personagem principal é uma menina. Por esse fato podemos retomar as mulheres cientistas que ficaram à margem da história da Ciência, falar sobre suas colaborações nesse campo do conhecimento, e que, da mesma forma que os homens, as mulheres podem sim fazer Ciência. Esse aspecto é evidenciado na fala da Aluna 12 que quando questionada sobre se as mulheres podem ser cientistas, ela responde: "eu acho que pode ser. Porque eu acho que todo mundo tem o direito de ser o que quer.". Porém, na maioria das falas, evidenciamos que nem todas as crianças pensam ou compreendem essas questões rela cionadas a o gênero e ciência. 
OLVEIRA, Luciana Rodrigues; MAGALHÃES, Joanalira Corpes. Esse é o Show da Luna: investigando gênero, ensino de ciências e pedagogias culturais. Domínios da imagem, v. 11, n. 20, p. 95-118, jan./jun. 2017.

ISSN 2237-9126

Por isso, ressaltamos a importância que desde cedo façamos essa discussão e este artefato toma-se uma potente ferramenta para tal reflexão.

\title{
Segundo movimento
}

Antes de assistimos perguntei se conheciam ou já tinham ouvido falar no desenho O Show da Luna, das dezoito crianças em aula, somente uma não conhecia o desenho. Após assistimos os vídeos conversamos sobre do que se tratavam os episódios. Em seguida, retomamos à aula (assistimos os episódios em uma sala de vídeo) e então chamei um a um para que respondessem as perguntas. A seguir apresentamos as perguntas e as falas de cada criança entrevistada.

\begin{abstract}
Aluna 1:
O que é ciência? - Pra mim ciência é tipo uma matéria que a gente estuda e a gente aprende...só que é uma matéria diferente.

Em qual momento do vídeo você percebeu ou não que havia ciência sendo feita? - Eu acho que não tem muita ciência mas tem imaginação.

Você a ssistiu outros desenhos relaciona dos à Ciência? - não. O que acha de uma mulher ser cientista? - é legal uma menina ser cientista.
\end{abstract}

\section{Aluna 2:}

O que é ciência? - Ciência acho que é...acho que é inteligente

Em qual momento do vídeo você percebeu ou não que havia ciência sendo feita? - Eu entendi que ela fez um projeto das borboletas, que ela pensou que era uma borboleta ela viu as borboletas conversou com elas. Teve ciência porque eu vi e gostei.

Você assistiu outros desenhos relacionados à Ciência? - Não lembro.

O que acha de uma mulher ser cientista? - Não tenho ideia.

\section{Aluna 3:}

O que é ciência? - ciência é pesquisar uma coisa e depois fazer essa coisa 
OLVEIRA, Luciana Rodrigues; MAGALHÃES, Joanalira Corpes. Esse é o Show da Luna: investigando gênero, ensino de ciências e pedagogias culturais. Domínios da imagem, v. 11, n. 20, p. 95-118, jan./jun. 2017.

ISSN 2237-9126

Em qual momento do vídeo você percebeu ou não que havia ciência sendo feita? - teve, por causa que eles sempre pesquisavam pra saber o que era.

Você assistiu outros desenhos relacionados à Ciência? - já, o inspetor bugiganga que ele faz uma poção que transforma todo mundo em gelatina.

O que acha de uma mulher ser cientista? - muito bom que daí aprende desde criança.

\section{Aluno 4:}

O que é ciência? - ciência..tem cientista que fazem umas fómula de laboratónio e inventam coisas.

Eé só no laboratório que se fazciência? - é.

Em qual momento do vídeo você percebeu ou não que havia ciência sendo feita? - em todos por causa que eles perguntavam as coisase sabiam dascoisas.

Você assistiu outros desenhos relacionados à Ciência? - não lembro.

O que acha de uma mulher ser cientista? - é a mesma coisa, mas pra mim é uma menina só.

\footnotetext{
Aluno 5:

O que é ciência? - ciência é uma coisa de tentar aprendera fazer coisas. Tipo coisas pra descobrir, tipo o que tem que fazer.

Em qual momento do vídeo você percebeu ou não que havia ciência sendo feita? - em alguns, porque eles pensavam que era pra fazer, pra descobrir.

Você a ssistiu outros desenhos rela ciona dos à Ciência? - não. O que acha de uma mulher ser cientista? - eu acho que pode ser. Porque a cientista trabalha em algumas coisas pra descobrir.

\section{Aluno 6:}

O que é ciência? - pra mim ciência é quando a gente faz uns invento maluco.

Em qual momento do vídeo você percebeu ou não que havia ciência sendo feita? todos, porque ela faz tudo pra aprender. Você assistiu outros desenhos rela ciona dos à ciência? - não. O que acha de uma mulher ser cientista? - Acho legal.
}

\footnotetext{
Aluno 7:

O que é ciência? - não sei.

Em qual momento do vídeo você percebeu ou não que havia ciência sendo feita? - não sei.

Você assistiu outros desenhos rela ciona dos à ciência? - não. O que ac ha de uma mulher ser cientista? - nada.
} 
OLVEIRA, Luciana Rodrigues; MAGALHÃES, Joanalira Corpes. Esse é o Show da Luna: investigando gênero, ensino de ciências e pedagogias culturais. Domínios da imagem, v. 11, n. 20, p. 95-118, jan./jun. 2017.

ISSN 2237-9126

\begin{abstract}
Aluno 8:
O que é ciência? - saber ler e escrever?

Em qual momento do vídeo você percebeu ou não que havia ciência sendo feita? - não sei.

Você a ssistiu outros desenhos rela ciona dos à ciência? - não.

O que acha de uma mulher ser cientista? - não sei.
\end{abstract}

\title{
Aluna 9:
}

O que é ciência? - nunca ouvi falar em ciência.

Em qual momento do vídeo você percebeu ou não que havia ciência sendo feita? - não sei.

Você a ssistiu outros desenhos relaciona dos à ciência? - não, a maioria é de conto de fada.

O que acha de uma mulher ser cientista? - nada.

\section{Aluna 10:}

O que é ciência? - é furacão? Quando eu ouvi falar eles tinham que inventar um furacão. A minha immã faz ciência e ela tem um monte de coisa em casa que tem uns produto. Ela faz vá rias coisas.

Em qual momento do vídeo você percebeu ou não que havia ciência sendo feita? - alguns porque ela perguntava ascoisas. Você assistiu outros desenhos relaciona dos à ciência? - tinha um vovô que fazia ciência mas não sei o nome. Acho que era Jack furacão o nome dele.

O que acha de uma mulher ser cientista? - acho que ela pode fazer ta mbém.

\section{Aluna 11:}

O que é ciência? - é uma coisa muito legal. Porque em casa adoro fazer ciência eu uso uns copinho que dá até pra fazer ciência.

Em qual momento do vídeo você percebeu ou não que havia ciência sendo feita? - em alguns porque ela adora fazer ciência ela tem uma imaginação e ela brinca de faz de conta aí ela fazque é os objeto. É muito engraçado.

Você assistiu outros desenhos relacionados à ciência? - O Show da Luna.

O que acha de uma mulher ser cientista? - legal.

\section{Aluna 12:}

O que é ciência?- ciência...eu acho que é uma coisa que a pessoa descobre as coisas pra saber o jeito que elas funcionam.

Em qual momento do vídeo você percebeu ou não que havia ciência sendo feita? - todos tinha porque eles estavam tentando descobrir o que que eram as coisas sim.

Você assistiu outros desenhos rela ciona dos à ciência? - não. 
OLVEIRA, Luciana Rodrigues; MAGALHÃES, Joanalira Corpes. Esse é o Show da Luna: investigando gênero, ensino de ciências e pedagogias culturais. Domínios da imagem, v. 11, n. 20, p. 95-118, jan./jun. 2017.

ISSN 2237-9126

O que acha de uma mulher ser cientista? - eu acho que pode ser. Porque eu acho que todo mundo tem o direito de ser o que quer.

\section{Aluna 13:}

O que é ciência? - ciência...eu acho que é algum tipo de texto. Não sei se é. Eaí a gente faz.

Em qual momento do vídeo você percebeu ou não que havia ciência sendo feita? - todos porque ela aprendeu aquelas coisas. Ela aprendeu a ser passarinho, ela aprendeu a ser lagarto várias coisas.

Você assistiu outros desenhos relacionados à ciência? - não lembro os nomes.

O que acha de uma mulher ser cientista? - acho que não. Não sei porque.

Ao analisar as falas das crianças sobre o que é ciência sete delas souberam dizer com suas palavras que a ciência é algo que tem que fazer experimentos, faz pesquisa através das perguntas e inventos. As dema is não souberam responder, algumas afimaram que nunca ouviram falar de c iência e outras perguntaram se é a lgum tipo de texto.

Quando perguntei se havia ou não ciência sendo feita no desenho, a maioria não soube dizer, contudo alguns disseram que havia sim pelo fato dos personagens (a Luna, seu imão e seu animal de estimação) esta rem fazendo perguntase buscando responderas mesmas.

Esses dados nos possibilitam analisar e ressaltar a importância das discussões relacionadas à Ciência estarem presentes no ensino desde a Educação Infantil, pois conforme observamos nas respostas das crianças, a maioria delas nunca teve conhecimento sobre o que se trata a Ciência. Isso mostra que "existe uma corrente de pensamento conservadora que não admite o direito à criança de fazer Ciência. Na verdade, é uma concepção preconceituosa e típica do dominador.[...]" (PAVÃO, 2014, p. 24).

Porém, segundo Ávila, Quadrado e Barros (2014, p. 35) “[...] Tanto nos RECNEl quanto os Parâmetros Curiculares Nacionais (PCN) destacam a importância de incorporar nos currículos da Educação Infantil e dos Anos Inic ia is os conhec imentos do campo das ciências. [...]". 
OLVEIRA, Luciana Rodrigues; MAGALHÃES, Joanalira Corpes. Esse é o Show da Luna: investigando gênero, ensino de ciências e pedagogias culturais. Domínios da imagem, v. 11, n. 20, p. 95-118, jan./jun. 2017.

ISSN 2237-9126

Embora esses documentos promovam a garantia de que os/as professores/as incluam essa área do conhecimento no cotidiano da sala de aula, na maioria das vezes isso não ocorre. Durante minhas observações e em meu estágio percebi que as áreas do conhecimento privilegiadas foram matemática e alfabetização. Trazemos essa problematização, pois,

Entendemos que o ensino de Ciências nos primeiros anos da Educação Básica é importante, pois propicia que as crianças começem desde cedo a se apropriar de uma linguagem científica e a construir conhecimentos que possibilitem que elas entendam o mundo que as cerca, interajam nas situações do cotidiano e tomem os conhecimentos que já possuem, provenientes de suas experiências, mais complexos. Assim, desde cedo, a linguagem científic a começa a fazer sentido para esses sujeitos. [...] (ÁVILA, QUADRADO, BARROS, 2014, p. 36-37)

Fazer com que a criança perceba que a ciência é tudo que noscerca é primordial para que ela entenda que elas também podem sim fazer ciência. Conforme Pavão,

[...] A observação de tudo que nos cerca, as plantas, os a nima is, o Sol, o vento, é sempre um bom começo, e que não tem fim, para observar, levantar hipóteses, medir, experimentar, fazer contas, ler, escrever, desenhar, divulgar, trocar, duvidar. (2014, p. 28)

Com isso podemos desmistificar que para fazer ciência é preciso ser gênio/a, estar em um laboratório, ser homem. É preciso que os/as alunos/as sintam prazer em aprender ciência, que questionem cada vez mais, que duvidem quando alguém disser que existe somente uma verdade.

Para as autoras Ávila, Quadrado e Barros,

Quando iniciamos desde cedo a utilizar certos procedimentos, recursos e metodologias, conseguimos discutir sobre como a Ciência é produzida em nossa sociedade, já que esta faz parte do nosso cotidiano, trazendo problemas, melhorias, 
OLVEIRA, Luciana Rodrigues; MAGALHÃES, Joanalira Corpes. Esse é o Show da Luna: investigando gênero, ensino de ciências e pedagogias culturais. Domínios da imagem, v. 11, n. 20, p. 95-118, jan./jun. 2017.

ISSN 2237-9126

tranformações, etc. Em um mundo em que os discursos e produções da Ciência adquirem destaque, toma-se necessário que o ensino de Ciências ocorra desde a Educação Infantil, para que os/as estudantes comecem, desde cedo, o processo de enculturação científica. (2014, p. 37)

Assim, queremos destacar a importância da compreensão dos fenômenos que ocorrem ao nosso redor, de se preocupar e tomar atitudes coerentes e críticas em diversas situações que acontecem no cotidiano. Aprender Ciência não é somente aprender fómulas ou ter que criar inventos, mas sim, aprender a questionar, duvidar, criar hipóteses, experimentar.

Ao perguntar se assistiram outros desenhos relacionados à ciência, apenas três crianças responderam qua is que assistiam, um deles é O Show da Luna, uma aluna mencionou o personagem inspetor bugiganga e uma menina falou de um desenho sobre um vovô o qual ela achava que se chama Jack furacão.

Os desenhos a nima dos têm grande influência sobre ascrianças, já que estes despertam interesse nas mesmas, pois contém uma linguagem lúdica e imagens com cores e formas que as atraem. E isso a caba por fortalecer sua memória auditiva e visual, que são de suma importância para o desenvolvimento cognitivo. O artefato cultural, nesse caso o desenho animado O Show da Luna “[...] É uma ferramenta que tem o poder de atrair as crianças e pode desenvolver seu intelecto e trabalhar sua ima gina ção.[...]" (SANTOS, PAUUNO, CRUZ, FLORIANO, 2016, p. 3)

Os artefatos cultura is estão presentes no cotidiano das crianças. Com isso, "a ideia de usar a TV, inerente às platafomas digitais a favor da educação, aproveitando a programação educativa para estimular o aprendizado e o pensamento reflexivo das crianças desde cedo, pode ajudar a formar um cidadão crítico.[...]" (SANTOS, PAUUNO, CRUZ, FLORIANO, 2016, p. 3) 
OLVEIRA, Luciana Rodrigues; MAGALHÃES, Joanalira Corpes. Esse é o Show da Luna: investigando gênero, ensino de ciências e pedagogias culturais. Domínios da imagem, v. 11, n. 20, p. 95-118, jan./jun. 2017.

ISSN 2237-9126

As cria nças têm suas própria s percepções sobre os a contec imentos ao seu redor, bem como tudo que faz parte da sua cultura. Elas se expressam pormeio de desenhos, falas, brinca deiras. As mesmas constroem signific ados próprios sobre os desenhos a nima dos e a rtic ula m esses com suas vivências e assim construindo sentido e signific ado.

Na última pergunta, quando questionei sobre o que achavam de uma mulher ser cientista, a maioria das crianças não soube opinar, algumas acharam legal e uma disse que não, mas não soube responder porque.

Atra vés desse dado pude analisar que a maioria das crianças não tem o mesmo pensamento dos adultos sobre a cultura das profissões femininas e masculinas. A criança que respondeu que acha que a mulher não pode ser cientista é a mesma que não soube responder o que é ciência, talvez pela criança não ter conhecimento sobre a ciência.

Durante o movimento feminista nos anos 50 e 60, começaram a ocorrer algumas mudanças. As mulheres ganharam mais visibilidade na sociedade machista e sexista. Historicamente as mulheres foram excluídas quando o assunto era sobre ciência, depois de muitos anos é que finalmente elasganharam reconhecimento na história da ciência. Porém,

[...] não devemos esquecer que a ciência é um empreendimento de caráter cumulativo e que seu passado do qual as mulheres foram excluídas - continua pesando sobre seu presente. Além disso, e apesar da feminização recente do mundo científico, os "grandes cientistas", aqueles que são percebidos como porta-vozes autorizados da ciência (prêmios Nobel, membros da Academia de Ciências, diretores de instituições prestigiosas ou de laboratórios de elite) são a inda geralmente do sexo ma sculino. (LÖWY, 2000, p. 24)

A ciência sempre foi vista como um campo masculino, como se somente os homens fossem inteligentes ao ponto de criarem, inventarem e reinventarem experimentos e formularem hipóteses. Como se as mulheres não pudessem atuar nessa profissão, infelizmente algumas mulheres se 
OLVEIRA, Luciana Rodrigues; MAGALHÃES, Joanalira Corpes. Esse é o Show da Luna: investigando gênero, ensino de ciências e pedagogias culturais. Domínios da imagem, v. 11, n. 20, p. 95-118, jan./jun. 2017.

ISSN 2237-9126

submeteram e ainda submetem-se a algumas coisas para poderem ser reconhecidase ter seu espaço nessa área do conhecimento. Segundo Lima,

\begin{abstract}
Atuar em espaços não considerados como próprios para as mulheres e orientados por valores androcêntricos impõe uma série de violências e dificuldades. As cientistas frequentemente reportam-se a momentos em que, para serem aceitas ou mesmo notadas, foi necessário passar por "testes" ou "provas" para garantir sua capacidade para ocupar uma deteminada posição. (2013, p. 890)
\end{abstract}

Sabe-se que ainda hoje há uma disputa muita grande sobre o "lugar" da mulher nas profissões consideradas masculinas. Como historicamente vivemos numa sociedade onde o homem é o centro das relações, quando uma mulher consegue um lugar de destaque na ciência, o homem faz de tudo para que a mulher não ganhe reconhecimento. Dentre os outros campos do conhecimento, o campo da ciência sempre foi disputado, pois todos que nele estão inseridos almejam uma posição privilegiada e de grande reconhecimento. Sabemos que

[...] Nas ciências, em situações de disputa de poder e quando outros argumentos não são suficientes para garantir uma determinada posição de poder, são utilizados argumentos considerados legítimos por si mesmos, como: senioridade, titulação, trajetória a ca dêmica (prêmios e cargos), localidade, área do conhecimento, raça e sexo. (LIMA, 2013, p. 890)

Também há questões sobre as mulheres terem que fazer o dobro de trabalho dos homens, para que possam "comprovar" sua capacidade e poder estar neste campo científico. Outra situação que ocorre, segundo Lima (2013, p. 893) é que "Para muitas mulheres, casar e ter filhos são fundamentais para sua realização plena. No entanto, o casamento e a matemidade a parecem em suas falas como importantes empecilhos para o progresso na carreira científica. ". As justificativas para que as mulheres não 
OLVEIRA, Luciana Rodrigues; MAGALHÃES, Joanalira Corpes. Esse é o Show da Luna: investigando gênero, ensino de ciências e pedagogias culturais. Domínios da imagem, v. 11, n. 20, p. 95-118, jan./jun. 2017.

ISSN 2237-9126

partic ipem deste campo são inúmeras. Aos poucos percebemos mudanças, masainda temos muito a avançar.

Assim, o desenho O Show da Luna nos possibilita promover essa discussão da história das mulheres na Ciência. Quando pensamos em cientistas a primeira imagem que nos vem à mente é a aparência, vemos um homem de jaleco branco, geralmente usando óculos, a fim de, demonstrar seriedade. Na escola raramente são mencionadas mulheres cientistas, como se fosse uma área somente masculina, de certa forma distinguindo o que é masculino e o que é feminino.

E não basta ser do gênero masculino para se fazer ciência, tem que se estar em um laboratónio equipa do para poder fazer expenimentos e formular hipóteses. Entende-se que para algo ser cientifico deve-se ser legitimado. E como se legitima? Legitima-se o conhecimento quando ocorre em um lugar legitimado, como por exemplo, escola, laboratónios e na universidade. Fazendo-se entender que a ciência é algo distante do sujeito, desse jeito desconsiderando todo conhecimento e experiências do mesmo.

As representações de gênero e ciência presentes no desenho O Show da Luna possibilitam questionar essas concepções que se tem sobre ciência, já que a protagonista é uma menina, não usa jaleco nem óculos, e não tem um laboratório. Para ela em qualquer lugar há muitas coisas para se descobrir.

\section{Considerações finais}

As análises das falas das crianças acerca do artefato cultural, o desenho animado O Show da Luna, possibilitaram discutir e problematizar os entendimentos que elas têm sobre o que é ciência, sobre o ser cientista e mulheres na ciência. Isso implica em perceber o entendimento delas sobre o que está representado em seu cotidiano. Também nos mostrou um dado muito importante, o de se discutir ciência desde a educação infantil, visto 
OLVEIRA, Luciana Rodrigues; MAGALHÃES, Joanalira Corpes. Esse é o Show da Luna: investigando gênero, ensino de ciências e pedagogias culturais. Domínios da imagem, v. 11, n. 20, p. 95-118, jan./jun. 2017.

ISSN 2237-9126

que a maioria das crianças entrevistadas nunca ouviu falar sobre essa temática.

Enfim, esse artefato mostra a possibilidade de abordar gênero e ciência desde a Educação Infantil, respondendo às crianças e aos questionamentos presentes em seu cotidiano. Artefatos cultura is que estão presentes em nossa sociedade, como potentes ferramentas pedagógicas a serem utiliza das na sa la de aula.

\section{Referências}

ALVARENGA, Darlan. Sucesso na TV e 'made in Brazil', Luna é o fenômeno infantil da vez. Disponível em «ttp://gl.globo.com/economia/midia-ema rketing/noticia/2016/02/ suc esso-na-tv-e-ma de-bra zil-luna-e-o-fenomenoinfantil-da-vez.html>. Acesso em: 15 de maio de 2016.

ANDRADE, Paula Deporte de. Pedagogias Culturais: as condições teóricas que possibilitam a emergência do conceito. বhttp://www.sbece.com.br/resources/a na is/3/ 1430005814_ARQ UIVO_sbece2 015c ompleto.pdf> Acesso em: 06/06/2016

ÁVILA, Dárcia Amaro; QUADRADO, Raquel Pereira; BARROS, Suzana da Conceição de. A chuva que cai, o arco-ínis que se forma... Repensando o ensino de ciências na educação infa ntil e nos a nos inicia is. In: RIBEIRO, Paula Regina Costa; MAGALHÃES, Joanalira Corpes (Org.). Ensino de Ciências: outros olha res, outras possibilidades. Rio Grande: FURG, 2014.

LMA, Betina Stefanello. O labininto de cristal: as trajetórias das cientistas na Física. Disponível em: \https:// periodic os.ufsc.br/index.php/ref/a rtic le/view/S0104026X2013000300007/26502>

LOURO, Guacira Lopes. Gênero, Sexualidade e educação: Uma perspectiva pós-estrutura lista. 15. ed. Petrópolis, RJ : Vozes, 2013.

LÖWY, llana. Universalidade da ciência e conhecimentos "situados". Disponível em: «tttp://www.bibliotec a digita l.unic a mp.br/ doc ument/? down $=51340>$ 
OLVEIRA, Luciana Rodrigues; MAGALHÃES, Joanalira Corpes. Esse é o Show da Luna: investigando gênero, ensino de ciências e pedagogias culturais. Domínios da imagem, v. 11, n. 20, p. 95-118, jan./jun. 2017.

ISSN 2237-9126

MAGALHÃES, Joanalira Comes. Corpos transparentes, exames e outras tecnologias médicas: a produção de saberes sobre os sujeitos homossexua is. 2012.

PAVÃo, Antonio Carlos. Ensinar Ciências fazendo ciência, por uma revolução pedagógica. In: RIBEIRO, Paula Regina Costa; MAGALHÃES, Joanalira Corpes (Org.). Ensino de Ciências: outros olhares, outras possibilidades. - Rio Grande: FURG, 2014.

ROSA, Russel Teresinha Dutra da. Repensando o ensino de Ciências a partir de novas histórias da ciência. In: OLVEIRA, Da isy Lara de (Org). Ciências nas salas de aula. Porto Alegre: Mediação, 1997. 112 p. (Cademos de Educação Básica, 2)

SANTOS, Pedro Paulo Procópio de Oliveira; PAULINO, Suzana Ferreira; CRUZ; Cristiane Ferreira; FLORIANO; J a ira Ita tiana. Desenhos a nima dos e educação na pré-escola: um estudo de caso dos principais canais infantis de TV no Brasil. Disponível em: বhttp://www.editora realize.com.br/revistas/conedu/trabalhos/TRABALHO_EV 056_MD1_SA19_ID11585_18082016173408.pdf> Acesso em: 17 nov. 2016.

SCHWANTS, Lavínia. Ciência: tanto se fala, pouco se define... In: RIBEIRO, Paula Regina Costa; MAGALHÃES, Joanalira Corpes (Org.). Ensino de Ciências: outros olhares, outras possibilida des. - Rio Grande: FURG, 2014.

SILVA, Elizabeth Bortolaia. Des-construindo Gênero em Ciência e Tecnologia. Disponível em: বhttp:// www.cei.santacruz.g12.br/ fisica/3UP_2015/DesconstruindoG\%C3\%AAnero-em-Ciencia-e-Tecnologia_cadpagu_1998_10_2_SILVA.pdf>. Acesso em: 22 maio 2016.

SILVA, Tomaz Tadeu da. Documentos de Identidade; uma introdução às teorias do cumíc ulo. 3. ed. Belo Horizonte: Autêntica, 2009. 